\title{
Changes of Literary Language in Digital Age
}

\author{
Chenyue Zhang* \\ Chongqing Youth Vocational \& Technical College, Chongqing 400712, China. E-mail: 121408928@qq.com
}

\begin{abstract}
Language forms and image-building in literary works are greatly influenced by media attributes in media ecology built by multimedia in the digital age. Through diachronic comparison between their development, information media and literary language are found to be positively related. From the perspective of the evolution of media form, this article makes analysis and discussion on the changes of Chinese literary language, seeking to provide foundation and guarantee for effectively popularizing literature and art among people.
\end{abstract}

Keywords: Media Industry; Literary Language; Mass Media; Main Performance

\section{Introduction}

No matter it is paper books or digital media, generally speaking, it is only an expression carrier of language for literary works, and its form isn’t related to the rhetorical features of literary language. In fact, the simple carrier theory obscures the two-way choice relationship between media and literary language ${ }^{[1]}$. On the one hand, in the stage of conception and creation of literary works, creators have an intentional presupposition of media form. In order to spread their thoughts and concepts well, it is necessary to choose the most effective media as the carrier. Different forms have different media attributes and language norms. Moreover, language will also be negatively restricted by the media, affecting its formal structure and aesthetic implication. On the other hand, media selection can influence reading experience of literary works, and different media often means the default of aesthetic taste and value orientation of specific communication technology forms. As an important category in human language system, literary language is derived from daily life and also carries the function of social information exchange. With the great changes in the form and style of the media, Chinese literary language has undergone corresponding changes and effectively adapted to the development of the times and the needs of knowledge and people's information acquisition in the digital age.

\section{Characterization of literary language changes in the digital age}

\subsection{From “elegance” to "superficiality"}

In China’s long era of feudal monarchy, the literacy rate was low, and literary works served the elites of rulers and literati as the core in both production and consumption fields. Meanwhile, the form of literary language was mainly classical Chinese with strong feature of elegance due to the limitations of material productivity and media forms at that time. Recently, with the rapid development of mass media, the characteristics of digital media, such as fragmentation, fast rhythm and strong interactivity, make language further dispel the purport of elegance and seriousness. Languages turn into colloquial expression in a more realistic context, which is manifested in the superficial form and ideographic

Copyright (C) 2020 Chenyue Zhang

doi: 10.18686/mcs.v2i4.1355

This is an open-access article distributed under the terms of the Creative Commons Attribution Non-Commercial License

(http://creativecommons.org/licenses/by-nc/4.0/), which permits unrestricted non-commercial use, distribution, and reproduction in any medium, provided the original work is properly cited. 
expression ${ }^{[2]}$. Being different from the "elegance” and "seriousness” of earlier literary works, current "network literature" and "mobile phone literature”, in particular, are in terms of daily life and form new representations of literary language in the digital age.

\subsection{From "seriousness" to "entertainment”}

Nowadays, the influence of digitalization is gradually expanding on people's daily life, which offers possibilities for plenty of literary authors to put their own works on the Internet. It effectively promotes the diversified development of Chinese literary forms. New literary works, such as online literature and fast-food fictions, become popular among people, which promoted the network evolution process of literary language ${ }^{[3]}$. From the content of literary works, the proportion of entertainment part involved in traditional Chinese literary works, is relatively small for a long time. Main purpose of a large number of works is to realize the inspiration and mobilization of readers' thoughts. Based on this, these works have strong sense of seriousness and solemnity. In the digital age, on the contrary, writing purpose of plenty of popular literature works is to please the readers. Therefore, a large number of entertaining languages is to express the content of articles. On this issue, there are currently two trends in the application of literary language in China. On the one hand, the use of language still maintains formal and serious in official and traditional literary works. On the other hand, works published in newspapers, magazines and other journals make use of entertaining language in order to attract users' attention.

\subsection{From "writing” to "visualization"}

In the media ecology, with the coexistence of multimedia integration in the digital age, literary language is no longer limited to the single form of traditional media. Instead, it integrates various ideographic forms, such as videos, pictures, sounds and characters, which improves the interaction between characters and other media ${ }^{[4]}$. Under the environment of media convergence, literary language is free from the restriction of single media for the first time. It absorbed nutrients from images and sounds, presenting the trend of visualization in the development progress. Visualization of literary language not only refers to the visualization of the medium carrying characters, but also goes deep into the formal structure and ideographic form. Attention has become a scarce product in the digital age. The visualized media form is more efficient in information dissemination. In many literary works, attention has been paid to the delicate depiction of the inner emotional world of the characters. There are more detailed description about external factors, such as scenes, plots, actions and dialogues. The visualized imagination space has been quickly constructed in the audience's mind with intuitive language ${ }^{[5]}$. Meanwhile, through the large-scale adaptations of online literature into film and television works in recent years, literary works in the digital age, in terms of the number of films and television adaptations as well as the effects after adaptation, are much better than traditional ones. The reason is that image-based information is of higher transmission efficiency, and literary creators living in the digital age have relatively little experience in emotional communication and expression. Moreover, many literary works are created with the initial purpose for the image-based adaptation.

\section{Analysis of the factors of literary language changes under the perspec- tive of digitalization}

In recent years, with the development trend of media integration driven by digitalization, the speed and scope of the dissemination of Chinese literary works have been expanded. During this process, information technology and multimedia platform have been rapidly developed, which further enlarged the number of literature readers. In this case, development and reform of language have been promoted. Researchers said that applications and expansions of Chinese vernacular have enhanced the atmosphere of new literary in China, which realized the change of its language. At the same time, the expansion of the literary market has enhanced the promotion and improvement of the entertainment and visualization level of Chinese literary language. It can be said that the revolutionary development of literary language in the digital age is an inevitable trend of literature and art in this new historical period. It is conducive to guid- 
ing literature and achieving a good survival in the new market and social environment ${ }^{[6]}$. The main reason for this change in the digital age is that the Internet users, mainly teenagers, have become the main readers of literary works. With the gradual developing number of readers, a corresponding literary market has formed. In the market, the demand for literary works has caused some authors to make self-examinations of their own works. Therefore, a large number of literary writers have analyzed the relevant contents in order to cater to audience's reading needs. During the process, many real-life languages and cases have been applied, which further promoted the popularization of literary language.

\section{Attitudes toward changes of literary language in the digital age}

Currently, there are differences in the attitudes of the public regarding the change of literary language. Among them, representative views mainly include two aspects. On the one hand, some think that under the influence of mass media, Chinese literary language has lost its traditional elegance and lead to the loss and weakening of the aesthetic feeling of literary language. On the other hand, some think that the change has enhanced the possibility of reading and understanding literary works better, which is of great significance and value to the development of Chinese literature ${ }^{[7]}$. Regarding the above viewpoints, researchers said that persons involved should learn to analyze related problems from a dialectical perspective when dealing with the changes of Chinese literary language in the digital age. It is an inevitable historical development for literary language changes, and it is also a developing method for literary and artistic. However, it is necessary for us to rightly view the development trend of literary language and absorb cultural essence. Besides, literary language also need to be popular instead of vulgar to avoid pan-entertainment problem and be conductive to the rational development of literature.

\section{Conclusion}

With the sweeping of digitalization in recent years, great changes have taken place in Chinese literary language. Based on this, the development trend of Chinese literature in the digital age has been questioned. Generally speaking, under the influence of the mass media, the status of literary language has gradually changed. Related language forms have made development in the direction of popularization. Regarding this problem, researchers believe that catering to the needs of the public and the market is the main factor that promotes the changes. Influenced by the needs of the audience, plenty of literary writers have made brand-new thoughts in their works, which effectively promotes the adjustment and transformation of literature in the new age. Some researchers express their lament regarding the loss of literature. However, the change in the digital age is a necessity for literature to develop and transform itself in a new historical period from a long-term perspective. Therefore, it is crucial to treat the change more rationally regarding the problem and lay a good foundation and guarantee for the development of literature in this new historical period.

\section{References}

1. Wang Y. The rhetoric of media and literature (in Chinese). Contention in Literature and Art 2003; (5): 8-10.

2. Zhang B. Media poetics: An introduction-Literature and literary theory under the media visual field [PhD thesis]. Hangzhou: Zhejiang University; 2005. p. 167.

3. Xia Y, Wang Z. A review on the study of literary language in the 30 years from 1980 to 2010. Journal of Sichuan University (Philosophy and Social Sciences Edition) 2013; (2): 82-87.

4. Wang $X$, Zhang S. On the aesthetic inheritance and social conventions of contemporary literary language. Contemporary Writers Review 2020; (4): 23-26, 16.

5. Wang P. Modern literary changes in the perspective of media culture-Comment on Jiang Xiaoli's modern Chinese mass media and modern Chinese literature (in Chinese). Contemporary Literary Criticism 2008; (1): 171-172.

6. Zhang W. Civilian position and folk expression in literary discourse: On the popular appeal, communication context and literary color of political ballads in the transitional period (in Chinese). Inner Mongolia Social Sciences 2012; 33(4): 154-158.

7. Meng Y. The characteristics and cognitive operation of the expression of "group makes wonderful" in media language (in Chinese). Modern Communication (Journal of Communication University of China) 2012; 34(9): 165167. 